\title{
Anestesia en cirugía de cadera en paciente con estenosis aórtica crítica. Rol del bloqueo iliofascial
}

\author{
Ficcadenti S. ${ }^{1}$, Frillocchi E. ${ }^{1}$, Moreno M. ${ }^{1}$, Negronida E. ${ }^{1}$
}

1 Hospital Fernández, Buenos Aires, Argentina.

Introducción: Se reporta la utilidad del bloqueo iliofascial guiado por ecografía y el manejo anestesiológico en una paciente de 100 años de edad con diagnóstico de estenosis aórtica crítica sometida a RAFI de cadera.

Descripción del caso: Paciente de sexo femenino de 100 años de edad cursando fractura medial de cadera derecha de 7 días de evolución es programada para RAFI de la misma.

Antecedentes:

1.Estenosis aórtica crítica.

2.Insuficiencia cardíaca.

3.HTA.

Examen físico:

Ingurgitación yugular 2/3. Crepitantes bibasales. Disnea clase funcional III.

Ecorcardiograma:

FSGVI severamente disminuida. Estenosis aórtica severa: vel. Pico 3,8 m/s, gradientes 58 y $34 \mathrm{mmHg}$, AVA 0,5 cm2.

Procedimiemto anestésico: Al ingreso: Sp02 96\% con cánula nasal; Fc 95x'; TA 145/55. Colocación acceso venoso $16 \mathrm{G}$ y catéter arterial. Se administra $1 \mathrm{ug} / \mathrm{kg}$ de fentanilo y $2 \mathrm{mg}$ midazolam. Se realiza bloqueo iliofascial ecoguiado con 25 cc de bupivacaína al 0,375\%. Simultáneamente al inicio de la cirugía, se inicia infusión de noradrenalina 0,05 $\mathrm{ug} / \mathrm{kg} / \mathrm{min}$. Fueron necesarios bolos intermitentes de fenilefrina. Tiempo quirúrgico: 75'. Sin cambios electrocardiográficos. Adecuado plano analgésico y manejo del dolor durante el acto quirúrgico. Se traslada a la paciente hemodinamicamente estable a UTI, donde evoluciona favorablemente sin exacerbación de su clínica de base. Sin cambios en ECG ni elevación de enzimas cardíacas.

Comentarios y Discusiones: Documentamos el uso del bloqueo de fascia ilíaca con sedación leve como única técnica anestésica para cirugía de cadera en paciente con estenosis aórtica crítica. Dada su seguridad, eficacia, adecuada analgesia y estabilidad hemodinámica, consideramos a este bloqueo una alternativa muy útil cuando el uso de anestesia general o subaracnoidea no son las opciones más adecuadas debido a su potencial compromiso hemodinámico asociado. Presenta un balance óptimo que satisface las necesidades quirúrgicas y hemodinámicas del paciente.

https://doi.org/10.25237/congresoclasa2019.78 